\title{
EL ARTE CONTRACULTURA EN LA DÉCADA DE LOS 80 EN EL PERÚ
}

\author{
Counterculture Art in the 80 s in Peru
}

\author{
Arturo Toledo Gonza ${ }^{1}$
}

\begin{abstract}
RESUMEN
El artículo trata sobre los acontecimientos artísticos sucedidos en el Perú en la década de los 80 en respuesta a los problemas socioculturales de carácter directamente contestatario de un grupo de artistas denominado Huayco, portador de un mensaje visual-conceptual. Es un arma de comunicación, una de las cualidades o su principal cualidad del arte contracultura es que sus propuestas desencajan nítidamente de los patrones escolásticos en el acabado de una obra de arte. De acuerdo con el artista plástico Herbert Rodríguez, las propuestas de contracultura o arte antisistema se originan en Lima, teniendo su punto de partida en las experiencias del "Arte no Objetual" creación que es resultado de la reflexión artística entendida como provocación, compromiso contestatario y enfrentamiento a un orden establecido.
\end{abstract}

Palabras claves: antisistema, contracultura, Huayco, libertad, contestatario.

\section{ABSTRACT}

The article is about the artistic events that took place in Peru in the 80 s in response to sociocultural issues of directly confrontational character of a group of artists called Huayco (avalanche) that carried a visualconceptual message. It is a weapon of communication; one of the qualities or its main quality is that counterculture art proposals do not fit clearlyb with those of the scholastics patterns in finishing a work of art. According to artist Herbert Rodriguez counterculture proposals or anti-art were originated in Lima, taking as their starting point in the experiences of the "no object art", creation that is the result of artistic reflection seen as provocative, confrontational engagement and confrontation to an established order.

Keywords: Anti-system, counterculture, Huayco, freedom, rebellious

\section{INTRODUCCIÓN}

\section{Arte contracultura}

La contracultura es un "paradigma que nos permite comprender el devenir de expresiones culturales alternativas a un sistema. Incluye manifestaciones artísticas, científicas, sociales, filosó- ficas, económicas y políticas, contrarias o diferentes a la cultura oficial, a la cultura del sistema; es una forma específica de ver la realidad, establece límites a lo hegemónico, formula interrogantes, introduce enigmas en el imaginario social" (Herrera, 2009, p. 73). La contracultura ha estado presente desde la anti-

\footnotetext{
${ }^{t}$ Licenciado en Arte. Docente de la Facultad de Ingeniería Civil, Arquitectura y Geotecnia de Ia Universidad Nacional Jorge Basadre Grohmann. Tacna-Perú.

Correoelectrónico:azul.mipensamiento@hotmail.com
} 
güedad. Algunos autores ven en Sócrates la primera manifestación contracultural. El filósofo griego representó en su momento el antisistema de la sociedad ateniense. Con sus enseñanzas rompió los moldes de una sociedad hipócrita y eso le valió el desprestigio efectuado por los sicofantes, difamadores profesionales al servicio de la clase dominante en Atenas, y luego la condena a muerte. Es sorprendente ver que todo lo que hoy sucede, no haya ocurrido ya en la extraordinaria Grecia, a la que estamos obligados a volver si queremos encontrar el fundamento de las cosas. Actualmente casi todos los medios de comunicación del planeta son sicofantes y obedecen al poder económico.

La contracultura aparece muchas veces sumergida y marginal por la enorme fuerza del imaginario social del sistema que establece creencias, gustos, morales, patrones anquilosados, los que a su vez crean modelos de conducta y de "comportamientos correctos» que originan represiones muchas veces feroces y terribles que no sólo pertenecen al pasado. Es al interior de este infierno que la contracultura se mueve para marcar nuevas tendencias y lograr cambios; no sólo en el sistema que asfixia y oprime, sino lograr que ese caminante que es el hombre se encuentre algún día a sí mismo. Si bien se ha insistido casi exclusivamente en la contracultura bajo su aspecto artístico, musical, cinematográfico, pictórico, etc, el movimiento real nos muestra que esta noción está presente en todas las áreas de la cultura que no sólo es arte sino que incluye todas sus expresiones. Quizás el aspecto más sonoro y más colorido de la contracultura se ha dado en el dominio del arte, pero en otras áreas la contracultura se ha expresado con mayor vigor y permanencia.

Como decía el historiador norteamericano Theodore Roszak en su libro
"El nacimiento de una contracultura" (1968), la contracultura son los valores, tendencias y formas sociales que chocan con lo establecido dentro de una sociedad.

La contracultura no busca un nuevo sistema, es sólo la lucidez frente a los sistemas dominantes a través de la historia.

\section{"La imaginación al poder"}

Ésta fue la frase acuñada por Jean Paul Sartre para situar Mayo del 68. La vida y la obra del pensador francés es el mayor ejemplo de lo que puede ser capaz el pensar contra el sistema e incluso contra sí mismo. Evitó siempre cualquier acto que lo comprometiera con el poder establecido y la cultura oficial. En una conversación sobre este tema con Simone de Beauvoir, Sartre le dice: "Los premios son concedidos a unos hombres por otros, y los hombres que conceden ese honor no tienen calidad para concederlo. Es como decir: Ud. pertenece a una clasificación; hemos transformado a la literatura en una realidad clasificada y Ud. está en tal o cual rango de esa literatura", (Herrera, 2009, p. 77).

\section{Antecedentes del arte contracultura}

\section{"Dadá" en Zurich}

El movimiento Dadá tuvo su espectacular punto de partida en Zurich en 1916, donde se enfrentan a la ideología académico-dogmática de las pequeñas burguesías suizas emigradas intelectuales de los más diversos orígenes, marcados por el destino de la primera guerra mundial. Según Hans Richter el "Arte Dadá y Anti-Arte estuvo presente cuando Arp y la poetisa Tristan Tzara hallaron el principio de la casualidad en sus experimentos artísticos" (Thomas, 1988, p. 100). Gracias a los escritos psicoanalíticos de C. G. Jung, que define la casuali- 
dad "como el orden fuera de la casualidad", y de Marcel Janco (1895) que integra el azar como "nuevo estímulo" en su creación artística al introducir materiales casualmente hallados, abandonados o en desuso, como alambres, plumas, vidrios ("objets trouves"), desarrollando trabajos de carácter contestatario.

"Dadá fue violento y desaforado. $\mathrm{Su}$ arte era producir la revolución entre sus seguidores dadaístas. [...] cuyas acciones revelaban una actitud desordenada pero febrilmente política. A través del núcleo Dadá en Berlín en 1919, los agentes provocadores asumirían militancias políticas" (Villacorta, 1996, p. 95). Además "el arte de compromiso político y de crítica social, se sirve de la provocación, la agitación y de la denuncia para la movilización de una conciencia social revolucionaria $[\ldots]$ y con unos montajes impresionantes y técnicas de pintura cartelísticas, que interpretan los temas socio-políticos actuales", (Thomas, 1988, p. 298-299).

\section{Características del arte contracultura}

a) El artista goza de la libertad de expresión en estos tiempos e incluye una multitud o variedad de elementos en la elaboración de sus obras, es más experimental y existe una clara tendencia a la multidisciplina y a la pluralidad estética. Entonces se puede decir que el artista del siglo XXI se identifica por la variación, la modificación y la experimentación.

b) Su composición es libre o abierta, contrario a toda forma impuesta por la voluntad formativa, rebelde a toda estructura preconcebida y racional.

c) Reutiliza materiales alternativos inusuales, desechos, escorias, absolutamente todo lo deseado que sea conveniente para la construcción de sus obras.

d) Cualquier soporte es un pretexto para un formato, muros de pared, latas, maderas, huesos, plásticos, etc.; todas las posibilidades que existen en su imaginación.

e) Sus principios están basados en las propuestas novedosas de lo absurdo, de lo carente de valor, como medio de expresión de un nuevo despertar hacia la problemática de la realidad.

f) Se involucra con la sociedad con el fin de despertar sentimientos, emociones y reflexiones.

\section{Significación y símbolo en el arte}

Mediante muchas observaciones de pinturas, esculturas, arquitecturas y mecanismos fabricados por el hombre, se llegó a ciertas conclusiones en todo lo que el hombre realizó a lo largo de la historia del arte; existe un mensaje que contiene una información buena o mala. Siempre que haya un símbolo, este esconde una significación que justifica al arte.

¿A qué nos referimos al hablar de arte y símbolo?... son preguntas sin fín que se han dado en la historia. Para tratar de entenderlas en qué consisten las obras de arte y qué simbolizan, enfatizaremos dos aspectos; el primero, consiste en el trabajo en si del artista, y, el segundo, en un inconsciente de expresividad de toda una sociedad donde éste habita. El artista transmite los gustos y disgustos del medio y podemos decir que aún en las manifestaciones artísticas del siglo XXI existen canales informativos llenos de símbolos que trasmiten un mensaje denominado artístico que consiste en una información consciente y la otra inconsciente, "en la historia el hombre ha recurrido siempre al arte como modo de expresión, para ello ha tenido que sistematizar, ordenar, codificar, formas e imágenes en símbolos que se enmarcan en aspectos que fundamentan la concepción iconográfica andina", (Liebscher, 
1986, p. 11). En ese sentido toda acción está determinada por un lenguaje que nos permite comprender la realidad u otras realidades siendo esta la importancia de los gráficos.

\section{Arte y contracultura peruana}

Una de las cualidades o la principal cualidad del arte contracultura es que sus propuestas desencajan nítidamente de los patrones con los que usualmente se pueden entender el acabado de una obra artística. Lo que importa es el valor de la obra en tanto se inserte en una realidad, en un contexto y asuma su momento y su rol como medio de revelación de la verdad que sistemáticamente se oculta.

Ese acto fundamental daría pie a propuestas igual de inquietas como las de arte correo, movidas subterráneas, arte crítico, etc.

El artista plástico Herbert Rodríguez también sostiene que el artista teje una suerte de historia. Dice: "Esta memoria critica de las propuestas contraculturales limeñas nace de mi voluntad de tener una voz propia para hablar de lo que considero una realidad objetiva. Existe una secuencia de propuestas alternativas, coherentes, sistemáticas, valiosas, igualmente silenciadas y eso me subleva. Ese es el origen de mi inquietud de asumir responsabilidades como teórico, además son propuestas que actúan no por oposición, sino como expresión de libertad individual pero comprometida con el drama del Perú" (Villacorta, 1996, p. 98).

El autor cuestionó también la validez de un arte hegemónico y plantea la interrogante: ¿Cómo se relacionan arte culto y arte popular en un proyecto compartido?

Resulta que el arte popular (el contra-arte, el no arte), se expresa por medios distintos como murales (graffi- ti), fotocopias, serigrafía, pintura esmalte, materiales reciclados, collage, etc. $Y$ ese es justamente el sentido del arte contracultural. Se trata de propuestas que se entroncan en una cultura urbana, proyectos jóvenes que están inmersos en un clima de desencanto social. Pero provistos de una visión crítica de la realidad y de lo que asumen como lo establecido, sistema excluyente, que con todo el derecho del mundo ellos cuestionan.

Según Mariátegui "el artista que no sienta las agitaciones, las inquietudes, las ansias de su pueblo y de su épo$\mathrm{ca}$, es un artista de sensibilidad mediocre, de comprensión anémica" (1988, p. 8). Su ideología "no puede salir de las asambleas de estetas; tiene que ser una ideología plena de vida, de emoción, de humanidad y de verdad; no una concepción artificial, literaria y falsa". Pero aún podemos añadir que estos alientos activos identifican al artista con el destino de su pueblo, lo compelen a expresar esperanzas y zozobras de sus gentes, por eso "el gran artista no fue nunca apolítico", no fue nunca un ente vegetativo y conformista. Por eso "el arte es esencial y eternamente heterodoxo".

\section{Grupo Huayco}

De acuerdo con el artista plástico Herbert Rodríguez las propuestas de contracultura $o$ arte antisistema se originaron en Lima, teniendo su punto de partida en las experiencias del "Arte no Objetual" del grupo Huayco, allá por los tempranos 80 recordado por su osada instalación "Sarita Colonia (La Santa no Oficial)" pintada sobre latas de leche recicladas, instaladas en los cerros contiguos a San Bartolo.

"La decisión de Huayco de dejar el espacio de la galería comercial, en el que en un principio había trabajado, para realizar una instalación en el kilómetro 54 de la Panamericana sur, ubica a 
la acción artística como creación de un espacio diferente para el intercambio humano, en el que lo político entre cruza con lo mágico - simbólico", (Villacorta, 1996, p. 96).

\section{La Cantuta}

Los acontecimientos que sucedieron en la época del terrorismo marcaron una etapa de zozobra en nuestra sociedad, con la captura de Abimael Guzmán en 1992 y los años que siguieron han sido, tal vez, testigos de una autocensura por parte de los artistas. Muchos son los que han sentido surgir un clima marcado por signos característicos de una casa de brujas.

Sin embargo, un hecho reciente determinó que algunas conciencias indi-

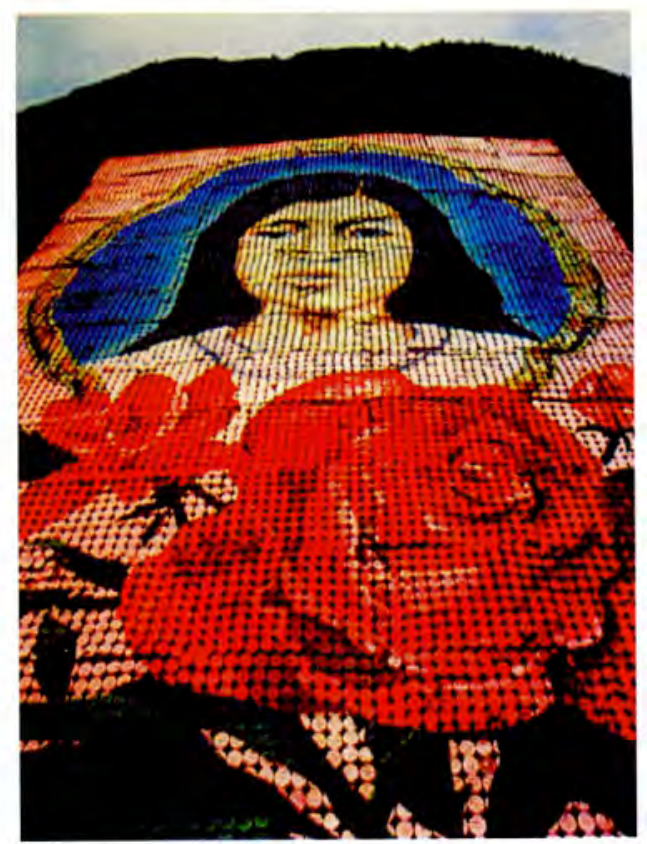

Figura 1. Sarita colonia, del grupo Huayco,1981. Kilómetro 54 de la Panamericana Sur, instaladas en los cerros contiguos a San Bartolo.

Configuración del rostro de la santa popular, objeto de un culto religioso no oficial, hecho con más de 10000 latas vacías de leche evaporada reciclada, pintadas y dispuestas a manera de alfombra. viduales asumieran una posición ética desde las artes visuales. Un comando policial de aniquilamiento victimó a 9 estudiantes y a un catedrático de la universidad Enrique Guzmán y Valle - La Cantuta - y enterró sus restos carbonizados en la quebrada de Cieneguilla en 1992.

El descubrimiento de los restos en 1993 gracias a información anónima recibida por la revista Sí, motivó rechazo y horror públicos.

Ricardo Wiesse (1954), artista plástico que se encuentra entre los más destacados y admirados actualmente, realizó en 1995 una acción ambiental en el sitio en que los restos fueron descubiertos. Del mismo modo, diseñó además un afiche al que acompañó la movilización de la coordinadora de Derechos Humanos en una campaña en contra de la amnistía otorgada a los asesinos, que ya habían sido identificados, juzgados y condenados.

Un tema importante fue la marcha en rechazo de la Ley de Amnistía a los asesinos de los desaparecidos de La Cantuta, que se realizó de la plaza Francia al Congreso, el 23 de junio de 1995, bajo la gestión de Eduardo Villanes. Fue un performance político callejero sui generis, de participación abierta, en el que se invitaba a cubrirse la cabeza con una caja de cartón de leche gloria.

\section{Denuncia y silencio}

En el año 1980 se vendrían las acciones de Sendero Luminoso, considerado al principio como un grupúsculo insignificante, con el correr de la década actuaría como un ejército invisible, implacable en la aniquilación y la destrucción del Estado y la sociedad peruana. El fracaso de la izquierda unida en proponer y promover un discurso ideológico urgentemente necesario frente al ascendiente de raíz maoísta del líder de 


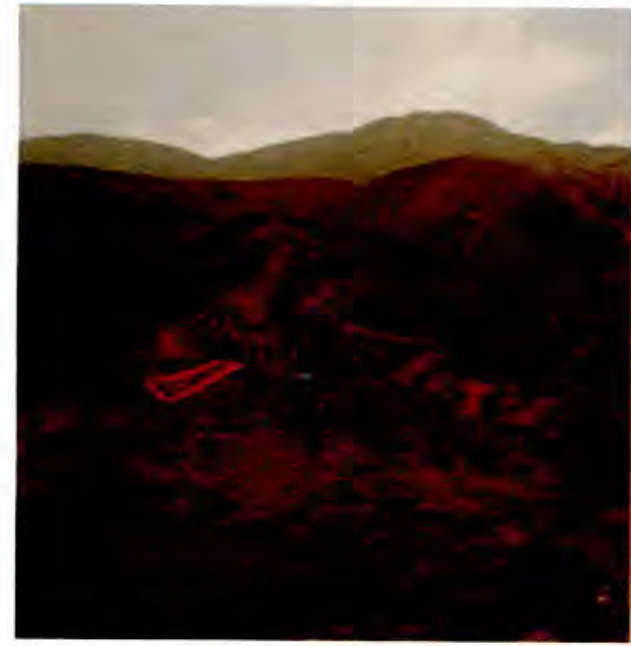

Figura 2. Afiche contra la impunidad, foto de Hermann Schwarz.

Imagen contra la Impunidad (homenaje póstumo a los estudiantes y profesor asesinados) elaborado por los artistas Manuel Figari y Ricardo Wiesse. Una plantilla de 3 metros de largo para reproducir 10 veces una flor de cantuta, depositando una mezcla de arena y tierra de color.

Sendero, Abimael Guzmán, así como frente al APRA, entronizada en el poder con la elección de Alan García como presidente, la debilitó y por último lo anuló como fuerza política.

La exposición de artistas visuales asociados (AVA), en la Alianza Francesa de Lima, 1983 - el año del asesinato de los periodistas en Uchuraccay - por ejemplo, reflejó el clima cultural en términos de tensión y desasosiego, asomo de psicosis y marcó una voluntad de interpelar críticamente al sistema estatal y social pero sin discurso verbal. Por el derecho a la vida en 1985, en la galería de la municipalidad de Miraflores, "fue ciertamente más decidida y coherente, tanto desde el punto de vista de la denuncia de desapariciones por la acción represiva del Ejército y la muerte violenta de inocentes a manos de Sendero Luminoso, como desde el trabajo artístico sobre un eje conceptual" (Villacorta, 1996, p. 97). Una acción denunciatoria y purificadora a la vez.

\section{Representantes del grupo Huayco}

- Francisco Mariotti, Maria Luy, Mariella Zevallos, Herbert Rodríguez, Charo Noriega, Armando Wiliams,

- Otros Artistas: Ricardo Wiesse, Colectivo: Por el derecho a la vida (instalación).

- Coordinador: Leslie Lee: Jesús Ruiz Durand, Lucy Angulo, Hugo Salazar del Alcázar, Mario Pozzi-Escot.

\section{CONCLUSIONES}

Concluimos que el arte contracultura produce la revolución entre los bien -pensantes, es portador de un mensaje visual-conceptual, es de carácter directamente contestatario, ubica a la acción artística como creación de un espacio diferente para el intercambio humano, es un arma de comunicación y afirmación en medio de la desinformación, los apagones, la represión y la muerte. Por ejemplo, la marcha en rechazo de la Ley de Amnistía a los asesinos de los desaparecidos de La Cantuta, de la Plaza Francia al Congreso, el 23 de junio de 1995 por Eduardo Villanes, político callejero.

Otra de las cualidades del arte contracultura o antiarte, son proyectos alternativos de propuestas que incitan a expresarse libremente sin restricciones o ataduras académicas.

También los materiales reciclados son una de las tantas alternativas para la composición en la obra del artista, a la vez son gratuitas y no habrá pretexto para la realización de las obras de arte.

Una de sus ventajas es que se puede utilizar cualquier espacio para su exhibición o intervención pública de las obras artísticas. 


\section{REFERENCIAS BIBLIOGRÁFICAS}

Herrera, Z. (2009). Filosofía y Contracultura. Quaderns de filosofia i ciencia. vol. 39, pp.73-82.

Liebscher, V. (1986). La iconografia de los Queros, Lima-Perú: Herrera Editores.

Mariategui, J. C. (1988). El artista y su época. Lima-Perú: Editorial Amauta.
Thomas, K. (1988). Hasta hoy estilos de las artes plásticas en el siglo XX. Barcelona, España: Ediciones del Serbal.

Villacorta, J. (1996). Quehacer. LimaPerú: Editorial Horizonte.

Wiesse, R. (2005). Papeles del vacío. Arte y paisaje en el Perú. Lima, Perú: Edición General/editors-in-chief. 